\title{
Constraints Faced by Farmers in Production of Inbred and Hybrid Rice in Udham Singh Nagar District of Uttarakhand, India
}

\author{
Ashish Prakash ${ }^{1}$, H.N. Singh ${ }^{1}$, R.S. Shekhawat ${ }^{2}$ and Surendra Sandu ${ }^{3}$ \\ ${ }^{1}$ Department of Agricultural Economics, GBPUA\&T University, Pantnagar, \\ U.S. Nagar, Uttarakhand, India \\ ${ }^{2}$ ICAR-Indian Agricultural Statistics Research Institute, New Delhi, India \\ ${ }^{3}$ ASI, Deg., Government of India \\ *Corresponding author
}

\begin{abstract}
A B S T R A C T
Rice is an important food crop which contributes nearly 39per cent to total food grain production in India. The population of our country has increased around 18 crores but production of rice increased by around 10 million tones in last decade. The level of rice production may not be sufficient to feed the ever increasing population in the future. The scope for expansion of area under rice has already been exhausted; the only way to increase the production is by increasing the productivity of rice through frontier

\section{Keywords}

Constraints, Production, Inbred, Hybrid rice.

Article Info

Accepted:

17 October 2017 Available Online:

10 December 2017 technologies. The hybrid rice may be potential technology to increase the average productivity level of rice in the country. Hybrid rice has potential to 20-30 per cent higher production than the inbred rice within same maturity duration as reported in previous studies. But farmers could not be able to realize higher yield of hybrid rice due to poor management practices, incidence of pest and diseases etc. The high seed cost of hybrid seed coupled with unawareness of management practices were restricting farmers for adopting recommended hybrid rice production technology. Thus the subsidy should be provisioned on seeds to reduce its cost for its popularization and promotion among the rice growers. Addition to it, training to the farmers on management practices of hybrid rice cultivation seems to be pre-requisite for successful harvest. Use of fertilizer and plant protection chemicals were found variables in different categories of farms, thus need for conduct demonstration of hybrid rice on farmer's field and awareness campaign on improved cultivation practices should be done. In this context there is a need to follow a strong extension program in the area regarding improved cultivation practices of hybrid rice. Such knowledge would serve as a guide to policy makers, producers and all those who are interested in increasing and mobilizing its potential and improving efficiency of various functions of production process and which would ultimately benefit the producers.
\end{abstract}

\section{Introduction}

Rice is the staple food for about 50per cent of the world's population that resides in Asia, where 90 per cent of the world's rice is grown and consumed. In Asia, India has the largest area under rice. It was 44.50 million hectares i.e., 29.40 per cent of the global rice area of the total harvested area, about 46 per cent is irrigated, 28 per cent is rainfed lowland, 12 per cent is rainfed upland and 14 per cent is flood prone. Rice is one of the largest traded 
commodities in the world with a total quantity touching 16.40 million tones. The South-east countries account for about 40 per cent of the rice trade in the world.

In many third world countries, it is main or the only source of livelihood for over 50 per cent of population and contributes roughly the same proportion to the national income (Tanveer Ahmed, 2006).

The state of Uttarakhand encompasses a geographical area of 53,483 sq. km. which accounts for 1.63 per cent of India's geographical area. Eleven out of thirteen districts in Uttarakhand fall under hills covering more than 75 per cent of the state geographical area. The mainstay of the economy in the state is agriculture even though it occupies only about 12.50 per cent of total area of state. The major crops produced in the state include rice, wheat, barley, corn, etc. (Singh et al., 2012).

Rice cultivation is important constituent of hill agriculture because rice is staple food of people of Uttarakhand. It is a main crop of the state and grown in an area of about 2.94 lakh hectares (2010-11) accounting for over 54 per cent of total area of cereal. The state having total production 5.50 lakh tones out of which plains and hills constitute about 3.72 (67.60 per cent) and 1.78 (32.40 per cent) lakh tones respectively. Average productivity of rice in the state is around 20.50 qtl. per ha.

Farmers in developing agriculture fail to exploit fully the potential of technologies and make allocative errors with the result that yields show wider variation, usually reflecting a corresponding variation in the management capacity of the farmers. This shows that considerable scope exists for raising productivity and income of the farmers by improving their efficiency.

\section{Materials and Methods}

A study was conducted to evaluate hybrid rice cultivation in Sitarganj and Kashipur blocks of Udham Singh Nagar district as these blocks having highest area under hybrid rice. A three stage sampling technique was employed for constructing sampling plan. In the first stage of sampling plan was the selection of blocks, selection of villages on second stage and respondent selection was done at on stage third. Probability proportion to size method technique was followed to select respondents which make a sample size of 60 farmers comprising of 28 small, 17 medium and 15 large farmers from 4 villages. This paper examines the constraints faced by farmers in production of inbred and hybrid rice. For examine the constraints Garrett ranking table was used.

\section{Results and Discussion}

\section{Constraint faced by farmers in production of inbred rice}

The result of constraints faced by famers in growing inbred varieties have been identified and presented in the Table 1. To analyze the constraint faced by farmers, in inbred rice cultivation were put before the sample farmers and farmers were asked to rank them according to the severity of constraints.

The ranks given by the farmers were converted into the average per cent position and then into scores. Finally, the scores were converted into the ranks with the help of Garrett ranking Table 2. It is evident from the table that the most severe constraint faced by farmers in growing inbred rice at overall level was high incidence of pest and disease (rank I) with garret score of 75 followed by Inadequate availability of fertilizers (rank II) at score 63 and unavailability of quality pesticides (rank III) with 56. 
Table.1 Ranking of various constraints faced by farmers in production of inbred rice

\begin{tabular}{|c|l|c|c|c|c|}
\hline \multirow{2}{*}{$\begin{array}{c}\text { Sl. } \\
\text { No. }\end{array}$} & \multicolumn{1}{|c|}{ Constraints } & \multicolumn{3}{c|}{ Rank } & \multirow{2}{*}{ Overall } \\
\cline { 3 - 4 } & & Small & Medium & Large & \\
\hline 1 & Low output price during harvesting & $5(48)$ & $3(59)$ & $5(51)$ & $4(53)$ \\
\hline 2 & Inadequate irrigation facilities & $9(30)$ & $10(28)$ & $10(27)$ & $10(29)$ \\
\hline 3 & High incidence of pest and disease & $1(75)$ & $1(76)$ & $1(74)$ & $1(75)$ \\
\hline 4 & High output price fluctuations & $6(47)$ & $7(43)$ & $6(46)$ & $5(45)$ \\
\hline 5 & Unavailability of quality pesticides & $4(57)$ & $2(62)$ & $4(53)$ & $3(56)$ \\
\hline 6 & Inadequate availability of labour & $8(37)$ & $9(38)$ & $8(41)$ & $8(39)$ \\
\hline 7 & Untimely rains & $3(62)$ & $8(41)$ & $3(55)$ & $6(50)$ \\
\hline 8 & Inadequate availability of fertilizers & $2(69)$ & $4(56)$ & $2(66)$ & $2(63)$ \\
\hline 9 & High cost of seeds & $10(23)$ & $5(50)$ & $9(37)$ & $9(35)$ \\
\hline 10 & Weed infestation & $7(46)$ & $6(45)$ & $7(42)$ & $7(43)$ \\
\hline
\end{tabular}

Note: Figures in parentheses indicates average score

Table.2 The transmutation of the order of merits into scores used in Garrett's ranking technique

\begin{tabular}{|c|c|c|c|c|c|c|c|}
\hline Per cent & Score & Per cent & Score & Per cent & Score & Per cent & Score \\
\hline 0.09 & 99 & 11.03 & 74 & 52.02 & 49 & 90.88 & 24 \\
\hline 0.20 & 98 & 12.04 & 73 & 54.03 & 48 & 91.67 & 23 \\
\hline 0.32 & 97 & 13.14 & 72 & 55.03 & 47 & 92.45 & 22 \\
\hline 0.45 & 96 & 14.25 & 71 & 58.03 & 46 & 93.19 & 21 \\
\hline 0.61 & 95 & 15.44 & 70 & 59.99 & 45 & 93.86 & 20 \\
\hline 0.76 & 94 & 16.65 & 69 & 61.94 & 44 & 94.03 & 19 \\
\hline 0.97 & 93 & 19.01 & 68 & 63.85 & 43 & 95.08 & 18 \\
\hline 1.20 & 92 & 19.20 & 67 & 65.75 & 42 & 95.62 & 17 \\
\hline 1.42 & 91 & 20.33 & 66 & 67.43 & 41 & 96.11 & 16 \\
\hline 1.63 & 90 & 22.32 & 65 & 69.39 & 40 & 96.57 & 15 \\
\hline 1.90 & 89 & 23.63 & 64 & 71.14 & 39 & 96.99 & 14 \\
\hline 2.03 & 88 & 26.43 & 63 & 72.85 & 38 & 97.37 & 13 \\
\hline 2.63 & 87 & 27.16 & 62 & 74.52 & 37 & 97.72 & 12 \\
\hline 3.01 & 86 & 28.66 & 61 & 76.12 & 36 & 98.04 & 11 \\
\hline 3.43 & 85 & 30.61 & 60 & 77.68 & 35 & 98.32 & 10 \\
\hline 3.89 & 84 & 32.42 & 59 & 79.17 & 34 & 98.68 & 9 \\
\hline 4.38 & 83 & 34.25 & 58 & 80.61 & 33 & 98.82 & 8 \\
\hline 4.92 & 82 & 35.15 & 57 & 81.99 & 32 & 99.03 & 7 \\
\hline 5.51 & 81 & 38.06 & 56 & 83.31 & 31 & 99.22 & 6 \\
\hline 6.14 & 80 & 40.01 & 55 & 84.56 & 30 & 99.39 & 5 \\
\hline 6.81 & 79 & 41.97 & 54 & 85.75 & 29 & 99.55 & 4 \\
\hline 7.55 & 78 & 42.97 & 53 & 86.89 & 28 & 99.68 & 3 \\
\hline 8.33 & 77 & 45.97 & 52 & 87.95 & 27 & 99.80 & 2 \\
\hline 9.17 & 76 & 47.98 & 51 & 88.97 & 26 & 99.91 & 1 \\
\hline 10.06 & 75 & 50 & 50 & 89.94 & 25 & 100 & 0 \\
\hline & & & & & & & \\
\hline
\end{tabular}


Table.3 Ranking of various constraints faced by farmers in production of hybrid rice

\begin{tabular}{|c|l|c|c|c|c|}
\hline Sl. No. & Constraints & \multicolumn{3}{|c|}{ Rank } & \multirow{2}{*}{ Overall } \\
\hline & & Small & Medium & Large & \\
\hline 1 & Unavailability of quality pesticides & $5(48)$ & $3(59)$ & $5(51)$ & $4(53)$ \\
\hline 2 & Inadequate irrigation facilities & $9(30)$ & $10(28)$ & $10(27)$ & $10(29)$ \\
\hline 3 & High cost of seeds & $1(75)$ & $1(76)$ & $1(74)$ & $1(75)$ \\
\hline 4 & Low output price during harvesting & $6(47)$ & $7(43)$ & $6(46)$ & $5(45)$ \\
\hline 5 & Inadequate availability of fertilizers & $4(57)$ & $2(62)$ & $4(53)$ & $3(56)$ \\
\hline 6 & Weed infestation & $8(37)$ & $9(38)$ & $8(41)$ & $8(39)$ \\
\hline 7 & High output price fluctuations & $3(62)$ & $8(41)$ & $3(55)$ & $6(50)$ \\
\hline 8 & High incidence of pest and disease & $2(69)$ & $4(56)$ & $2(66)$ & $2(63)$ \\
\hline 9 & Inadequate availability of labour & $10(23)$ & $5(50)$ & $9(37)$ & $9(35)$ \\
\hline 10 & Untimely rains & $7(46)$ & $6(45)$ & $7(42)$ & $7(43)$ \\
\hline
\end{tabular}

Note: Figures in parentheses indicates average score

The constraints faced by medium size farmers growing inbred rice was high incidence of pest and disease (rank I) with garret score of 76 followed by unavailability of quality pesticides (rank II) at score of 62 and low output price during harvesting (rank III) with score 59, while in case of large farmers the major constraints faced were high incidence of pest and disease (rank I) with score of 74 inadequate availability of fertilizers (rank II) with score of 66 untimely rains (rank III) with score of 55.

\section{Constraint faced by farmers in production of hybrid rice}

The result of major constraints faced by farmers in growing hybrid rice has been presented in Table 3. It is evident from the that most severe constraint faced by growing of hybrid rice was high seed cost (rank I) with garret score of 75 followed high incidence of pest and disease (rank II) and inadequate availability of fertilizers (rank III) with garret score of 63 and 56, respectively.

Major constraint faced by medium size farmers in growing of hybrid rice were high cost of seeds (rank I) with garret score of 76 followed inadequate availability of fertilizers (rank II) and unavailability of quality pesticides (rank III) with garret scores of 62 and 59, respectively.

In case of large farmer in growing of hybrid rice, high cost of seeds (rank I) with a score of 74 , high incidence of pest and disease (rank II) and high output price fluctuations (rank III) were identified as the major constrains. These are in agreement with findings of (Nguyen and Baldeo, 2006).

Production constraints are discouraging the growers to augment the production of hybrid rice. Efforts should be made for vital inputs particularly seeds, fertilizers and pesticides at reasonable prices and in adequate quantities to the farmers at required time.

In this context, strengthening of input delivery system in the area is urgently warranted. Also, less expensive and effective measures for the control of serious insect-pests and diseases should be undertaken.

If these issues are seriously considered, then hybrid rice production will definitely receive a boost which will in turn create benefits for the growers and the state can even increase its revenue through rice export to other states. 


\section{References}

Ahmed, T. 2006. An economic analysis of paddy based farming systems in Southern Karnataka- A case study of Mandya district. M. Sc. Thesis submitted to Department of Agricultural Economics, University of Agricultural Sciences, Dharwad.

Atibudhi, H.N. 1993. An economic analysis of rice based cropping system. Agricultural situation in India, 47 (12): 71-77.

Nguyen, C. T. and Baldeo, S. 2006. Constraints faced by the farmers in rice production and export in India and Vietnam. Cuu Long Delta Rice Research Institute and Head of the Division of Agricultural
Extension, IARI, New Delhi, India.

Nirmala, B. and Muthuraman, P. 2009. Economic and constraint analysis of rice cultivation in Kaithal district of Haryan, Indian Res. J. Ext. Edu. 9 (1)

Singh and Varshney 2009. Adoption level and constraints in rice production technology in Jabalpur district of Madhya Pradesh, Indian Research Journal of Extension Education. 10. (1.).

Singh, H. N., Singh, S. P., Singh, U. S., Singh, J., Zaidi N. W. and Mohanty, S. 2013. Economic evaluation of Pusa Rice Hybrid10 cultivation: a microeconomic evidence of Uttarakhand, India Ind. J. Traditional knowledge, 12(3): 472-477.

\section{How to cite this article:}

Ashish Prakash, H.N. Singh, R.S. Shekhawat and Surendra Sandu. 2017. Constraints Faced by Farmers in Production of Inbred and Hybrid Rice in Udham Singh Nagar District of Uttarakhand, India. Int.J.Curr.Microbiol.App.Sci. 6(12): 2243-2247. doi: https://doi.org/10.20546/ijcmas.2017.612.259 